\title{
Genetic Diversity of Wild Peach (Prunus mira Koehne kov et. kpst) from Different Altitudes in the Tibetan Plateau by Pollen Morphous and RAPD Markers
}

\author{
Fachun Guan \\ Agriculture and Animal Husbandry College, Tibet University, Linzhi, Tibet \\ 860000, P.R. China; and the Institute of Tibetan Plateau Research, Chinese \\ Academy of Sciences, Beijing 100101, China
}

\author{
Shiping Wang \\ Institute of Tibetan Plateau Research, Chinese Academy of Sciences, Beijing \\ 100101, China
}

\section{Rongqin Li}

Agriculture and Animal Husbandry College, Tibet University, Linzhi, Tibet 860000, P.R. China

\section{Mu Peng and Fanjuan Meng ${ }^{1}$ \\ College of Life Science, Northeast Forestry University, No. 26 Hexing Street, Harbin 150040, P.R. China}

\begin{abstract}
Additional index words. evolutionary, pollen characteristics, relationship, scanning electron microscope, variation
\end{abstract}

\begin{abstract}
To analyze the evolutionary level of Prunus mira Koehne (Prunus mira Koehne Kov et. Kpst), 15 kinds of pollen grains from five altitudes were observed using a scanning electron microscope (SEM). This study demonstrates that pollen morphous $P$. mira has high variation; specifically, individuals from higher altitudes are much more evolved than those from lower altitudes. This is the first time the pollen morphology of $P$. mira has been systematically illustrated. Furthermore, 12 random amplified polymorphic DNA (RAPD) primers generated clear and repeatable bands among all individuals based on RAPD; 107 bands ranging from 200 bp to 2000 bp were generated with an average of 8.92 bands per primer. Thus, the RAPD technique proved to be a powerful tool to reveal variation on $P$. mira. This study provides comprehensive information for genetic diversity of $P$. mira from different altitudes.
\end{abstract}

The highest plateau in the world is the Tibetan Plateau, which reaches mean altitudes of 4000 to $5000 \mathrm{~m}$. High radiation, strong winds, cold temperatures, and drought characterize the harsh environment of the Tibetan Plateau. As a result of these rigorous conditions and inaccessibility of the Tibetan Plateau, few studies regarding the genetic diversity in plant populations have been conducted (Guo et al., 2006). Prunus mira Koehne (Prunus mira Koehne Kov et. Kpst)

Received for publication 21 May 2014. Accepted for publication 15 June 2014.

This project was supported by the Fundamental Research Funds for the Central Universities (DL13EA08-2) and the National Natural Science Foundation of China (No. 31160386; 31201594), National Science and Technology Support Program (2011BAI13B06) and Tibet's innovation project from Chinese Academy of Sciences.

${ }^{1}$ To whom reprint requests should be addressed; e-mailmfj19751@163.com. species is mainly distributed within the altitude range of 2500 to $3600 \mathrm{~m}$, where the mean annual temperature is approximate 6 to $13{ }^{\circ} \mathrm{C}$ and the soil texture is typically sandy, semisandy, or loam soil (Guo et al., 2006). Therefore, to adapt and thrive in this harsh environment, it has developed characteristics such as a tolerance to drought conditions and cold temperatures, resistance to disease, and infertility (Wang et al., 1997). Accordingly, $P$. mira has attracted considerable attention and should be used as a gene source to develop new resistant peach species. Additionally, because of fast-growing, exuberant leafy branches and the presence of luxuriant blossoms, $P$. mira has been used as an ornamental plant (Tan et al., 2001). To date, many of studies of this remarkable plant have focused on morphological variability, multiplication, and the physiology of $P$. mira. However, there are few detailed studies on the genetic diversity of $P$. mira based on pollen morphology or the molecular markers.

Generally, the pollen features of a plant can be used as markers of inheritance in taxonomic researches. In other words, we can identify plants from their pollen morphology (Adekanmbi and Ogundipe, 2006; Noor et al., 2004; Perveen and Qaiser, 2010). Therefore, understanding characteristics of pollen morphology is significant to reveal disputable taxonomic and phylogenetic arguments, which can be considered related to evolutionary characteristics (Oswald et al., 2011). Some studies demonstrated that mountain plants have been found to show remarkable genetic differentiation among populations because a relatively minimal altitudinal change can result in a large alteration in environmental conditions such as temperature and humidity (Hirao and Kudo, 2004; Isik and Kara, 1997).

Additionally, a lot of methods have been used to assess the genetic relationships in plant species. Among these methods, RAPD is a fast and inexpensive technique (Debener et al., 1996). In the past decade, RAPD has been used for constructing linkage mapping, analyzing genetic diversity, and determining phyletic evolution in many plant species such has been recognized as an important wild peach species in China, which is indigenous to the Tibetan Plateau (Dong, 1991). This
Table 1. Parameters of pollen grains from different altitudes.

\begin{tabular}{|c|c|c|c|c|c|c|}
\hline Code & $\begin{array}{l}\text { Altitud } \\
(\mathrm{m})\end{array}$ & $\begin{array}{c}\mathrm{DBH} \\
(\mathrm{m})\end{array}$ & $\begin{array}{l}\text { Equatorial } \\
\text { axis }(\mu \mathrm{m})\end{array}$ & Polar axis $(\mu \mathrm{m})$ & Sexine ornamentation & Figure \\
\hline 1 & 2900 & 0.5 & $31.16 \pm 0.12$ & $63.71 \pm 0.13$ & 2.05 Striate, sculpture blur & Figure 1-1 \\
\hline 2 & 2900 & 1.2 & $31.56 \pm 0.13$ & $60.45 \pm 0.02$ & 1.92 Striate, sculpture blur & Figure $1-2$ \\
\hline 3 & 2900 & 1.9 & $30.52 \pm 0.11$ & $60.50 \pm 0.23$ & $\begin{array}{l}1.98 \text { Striate - perforate, sculpture blur } \\
\text { or sharp }\end{array}$ & Figure 1-3 \\
\hline 4 & 3000 & 0.9 & $32.30 \pm 1.01$ & $66.66 \pm 0.12$ & 2.06 Striate - perforate, sculpture sharp & Figure 2-1 \\
\hline 5 & 3000 & 1.2 & $31.88 \pm 0.96$ & $63.80 \pm 1.23$ & 2.01 Striate - perforate, sculpture sharp & Figure $2-2$ \\
\hline 6 & 3000 & 1.5 & $33.59 \pm 0.56$ & $67.11 \pm 0.26$ & 2.00 Striate-perforate, sculpture blur & Figure 2-3 \\
\hline 7 & 3100 & 0.8 & $32.96 \pm 0.23$ & $65.11 \pm 1.00$ & 1.98 Striate - perforate, sculpture sharp & Figure 3-1 \\
\hline 8 & 3100 & 1.0 & $7 \pm 0.24$ & $65.78 \pm 0.23$ & 2.06 Striate, sculpture sharp & Figure 3-2 \\
\hline 9 & 3100 & 1.3 & 32.4 & 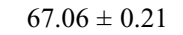 & 2.07 Stri & Figure 3-3 \\
\hline 10 & 3150 & 0.5 & $33.05 \pm 0.21$ & $65.60 \pm 0.23$ & 1.99 Striate - perforate, sculpt & Figure 4-1 \\
\hline 11 & 3150 & 0.8 & $31.25 \pm 0.16$ & $64.51 \pm 0.10$ & 2.07 Striate - perforate, sculpture sharp & Figure $4-2$ \\
\hline 12 & 3200 & 1.4 & $31.73 \pm 0.15$ & $65.75 \pm 0.02$ & 2.07 Striate, sculpture sharp & Figure $5-1$ \\
\hline 13 & 3200 & 2.0 & $33.74 \pm 0.17$ & $68.14 \pm 0.01$ & 2.02 Striate, sculpture sharp & Figure 5-2 \\
\hline 14 & 3200 & 2.2 & 0.06 & $68.02 \pm 0.01$ & 1.97 Irregular - perforate, sculpture sha & Figure $5-3$ \\
\hline 15 & 3150 & & & ollen grain & in be observed, maybe male sterile & \\
\hline
\end{tabular}

$\mathrm{DBH}=$ diameter at breast height; $\mathrm{P} / \mathrm{E}=$ the ratio of polar axis and equatorial axis. 
as tomato (Lin et al., 2006), rose (Debener et al., 1996), potato (Alfonso and Bamberg, 2000), and bean (Marotti et al., 2007). However, RAPD had yet to be used for the identification of genetic diversity on $P$. mira until now.

The following is a documentation of taxonomic evidence and offers a preliminary result for genetic diversity of $P$. mira from five different altitudes. The samples were analyzed using SEM and RAPD. The following questions will be answered as a result of the analysis: 1) What are the pollen characteristics of $P$. mira? 2) Is there a relationship between pollen morphology variation and altitude? 3) Is there a relationship between genome variation and altitude?

\section{Material and Methods}

Plant materials. In this study, all pollen samples were obtained from the Tibetan Plateau and their information is listed in Table 1 . We selected five different altitudes that range from $2900 \mathrm{~m}$ to $3200 \mathrm{~m}$. Three random individuals of $P$. mira were selected at each altitude. To avoid mixture of pollen grains, all samples collected were buds that nearly bloomed and each was placed into specimen bags separately.

Observation of pollens. Before the observation of the pollen, the buds were stripped and the pollen grains were scraped onto adhesive tape by a nail under an anatomy microscope. Then the pollen samples were coated with gold and transferred to the SEM (HITACHI-520; Electron Microscope Center, Biotechnology Center, Northeast Agriculture University, P.R. China) for SEM studies. The terminologies on pollen morphology were according to the viewpoints of Ishik and Kara (Isik and Kara, 1997). The following parameters were measured: length of the equatorial axis, length of the polar axis, and the ratio of the polar axis and the equatorial axis according to the 30 individual pollen grains. A dendrogram according to the parameters from pollen morphous was constructed using SPSS 16.0 software (SPSS Inc., Chicago, IL).

DNA extraction. Genomic DNA from individual samples was extracted from $0.2 \mathrm{~g}$ of fresh young leaves from each and stored at $-20^{\circ} \mathrm{C}$ for RAPD amplification. Fifty RAPD random primers were used for polymerase chain reaction (PCR) amplification, of which 12 primers generated clear, reproducible banding patterns and were selected for further analysis. The codes and sequences of 12 primers are listed in Table 2. Because no. 15 had no pollen, the total DNA was not extracted. All primers were synthesized in Shanghai Sangon Biological Engineering Technology and Service Co. Ltd., Shanghai, China.

RAPD amplification. PCR reaction was performed in a volume of $20 \mu \mathrm{L}$ containing $0.5 \mathrm{~mm}$ of dNTPs (Promega, Beijing, China), $0.2 \mu \mathrm{M}$ primer, $30 \mathrm{ng}$ template DNA, $1 \mathrm{U}$ Taq polymerase (TaKaRa, Dalian, China), $2 \mu \mathrm{L}$ of $10 \times$ PCR buffer $(\mathrm{TaKaRa})$, and $1.8 \mathrm{~mm}$ $\mathrm{Mg}^{2+}$ (TaKaRa). PCR amplifications were carried out in a DNA thermocycler (GeneAmp PCR System 9700). Preliminary denaturation was performed at $94{ }^{\circ} \mathrm{C}$ for $4 \mathrm{~min}$ followed by 45 cycles of $94{ }^{\circ} \mathrm{C}$ for $1 \mathrm{~min}$, $36^{\circ} \mathrm{C}$ for $1 \mathrm{~min}$, and $7^{\circ} \mathrm{C}$ for $2 \mathrm{~min}$. After 45 cycles, there was a final extension for 10 min at $72{ }^{\circ} \mathrm{C}$. The amplification products were separated on $1.5 \%(\mathrm{w} / \mathrm{v})$ agarose gel. Each experiment was performed three times.

Data analysis. RAPD bands were scored as present (1) or absent (0), and the binary character matrices were compiled with the results. The genetic diversity coefficient was calculated using the NTSYS program (Rohlf,
1992). The data were analyzed by the total number of bands (TNB), the number of polymorphic bands (NPB), and percentage of polymorphic bands (PPB). The dendrogram was then constructed using unweighted pair group method with arithmetic mean (Rohlf, 1992).

Based on the bands analyses, pairwise genetic distance (GD) between accessions $i$ and $j$ were estimated using the similarity coefficient as follows:

$$
\mathrm{GD}=2 N i j /(N i+N j)
$$

where $N i$ and $N j$ are the numbers of amplified alleles in the accessions $i$ and $j$, respectively.

Table 2. Sequences of 12 primers and the results of amplification.

\begin{tabular}{llccc}
\hline Primer & Sequence 5' - $^{\prime}$ & $\begin{array}{c}\text { Total number } \\
\text { of bands }\end{array}$ & $\begin{array}{c}\text { Number of } \\
\text { polymorphic bands }\end{array}$ & $\begin{array}{c}\text { Percentage of polymorphic } \\
\text { bands (\%) }\end{array}$ \\
\hline S119 & CTGACCAGCC & 12 & 8 & 66.67 \\
S20 & GGACCCTTAC & 9 & 7 & 77.78 \\
S14 & TCCGCTCTGG & 11 & 11 & 100.00 \\
S29 & GGGTAACGCC & 6 & 2 & 33.33 \\
S30 & GTGATCGCAG & 4 & 4 & 100.00 \\
S31 & CAATCGCCGT & 10 & 10 & 100.00 \\
S47 & TTGGCACGGG & 11 & 10 & 90.92 \\
S48 & GTGTGCCCCA & 5 & 4 & 80.00 \\
S58 & GAGAGCCAAC & 10 & 8 & 80.00 \\
S65 & GATGACCGCC & 10 & 4 & 40.00 \\
S76 & CACACTCCAG & 9 & 7 & 77.78 \\
S96 & AGCGTCCTCC & 10 & 10 & 100.00 \\
Sum & & 107 & 85 & 946.48 \\
Mean & & 8.92 & 1.83 & 78.87 \\
\hline
\end{tabular}

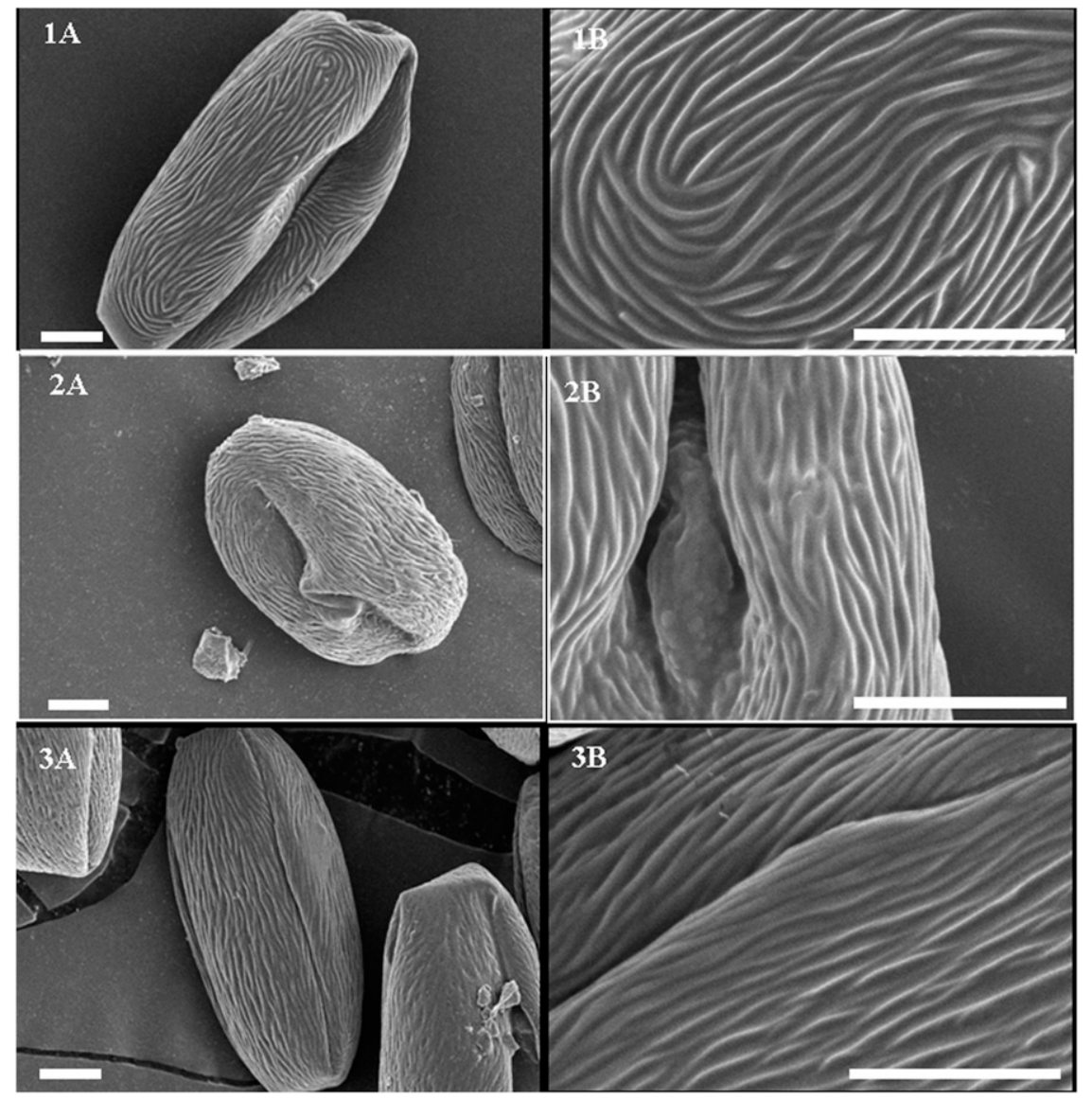

Fig. 1. Pollen morphous of P. mira from $2900 \mathrm{~m}$. 


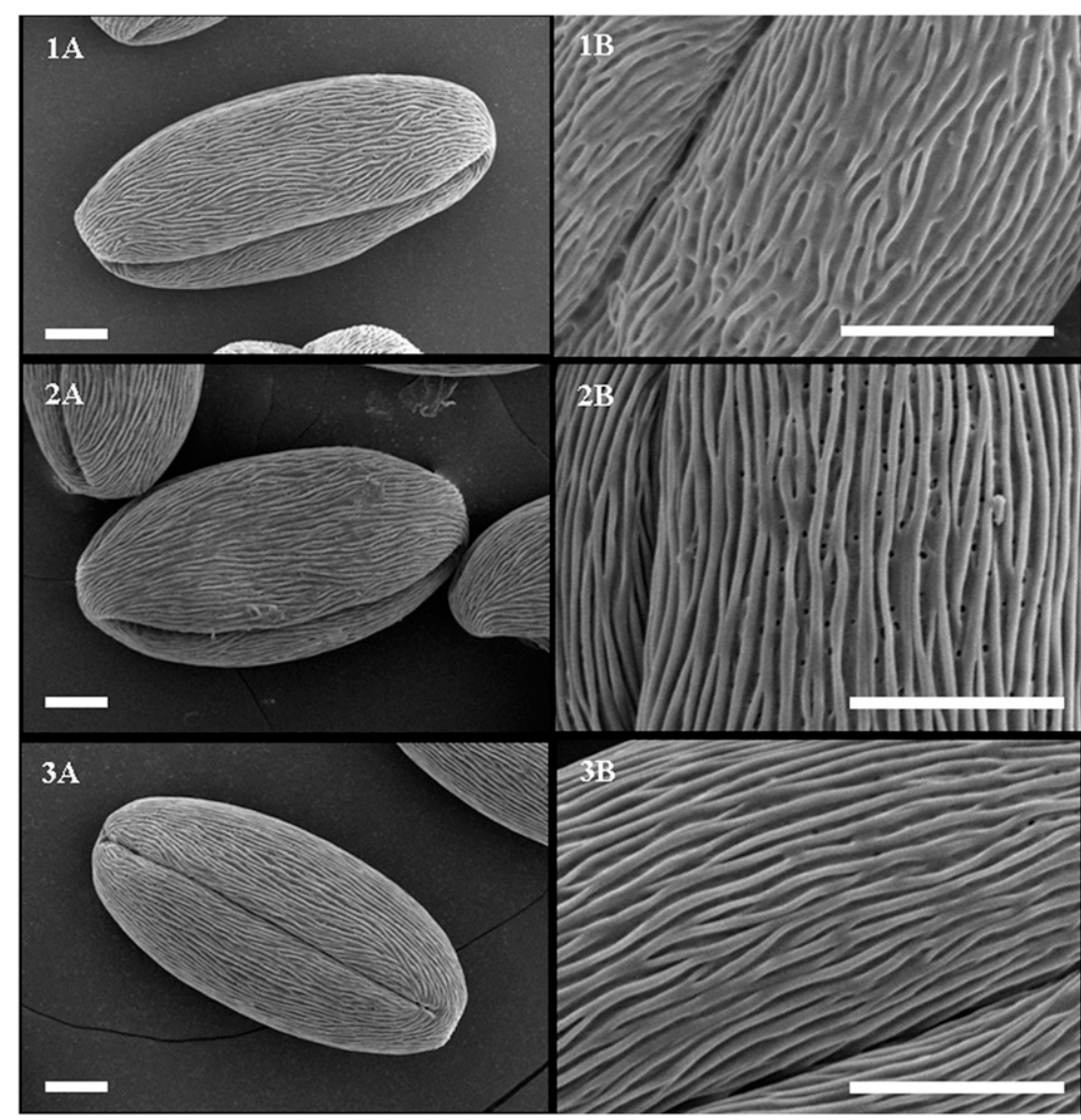

Fig. 2. Pollen morphous of $P$. mira from $3000 \mathrm{~m}$.

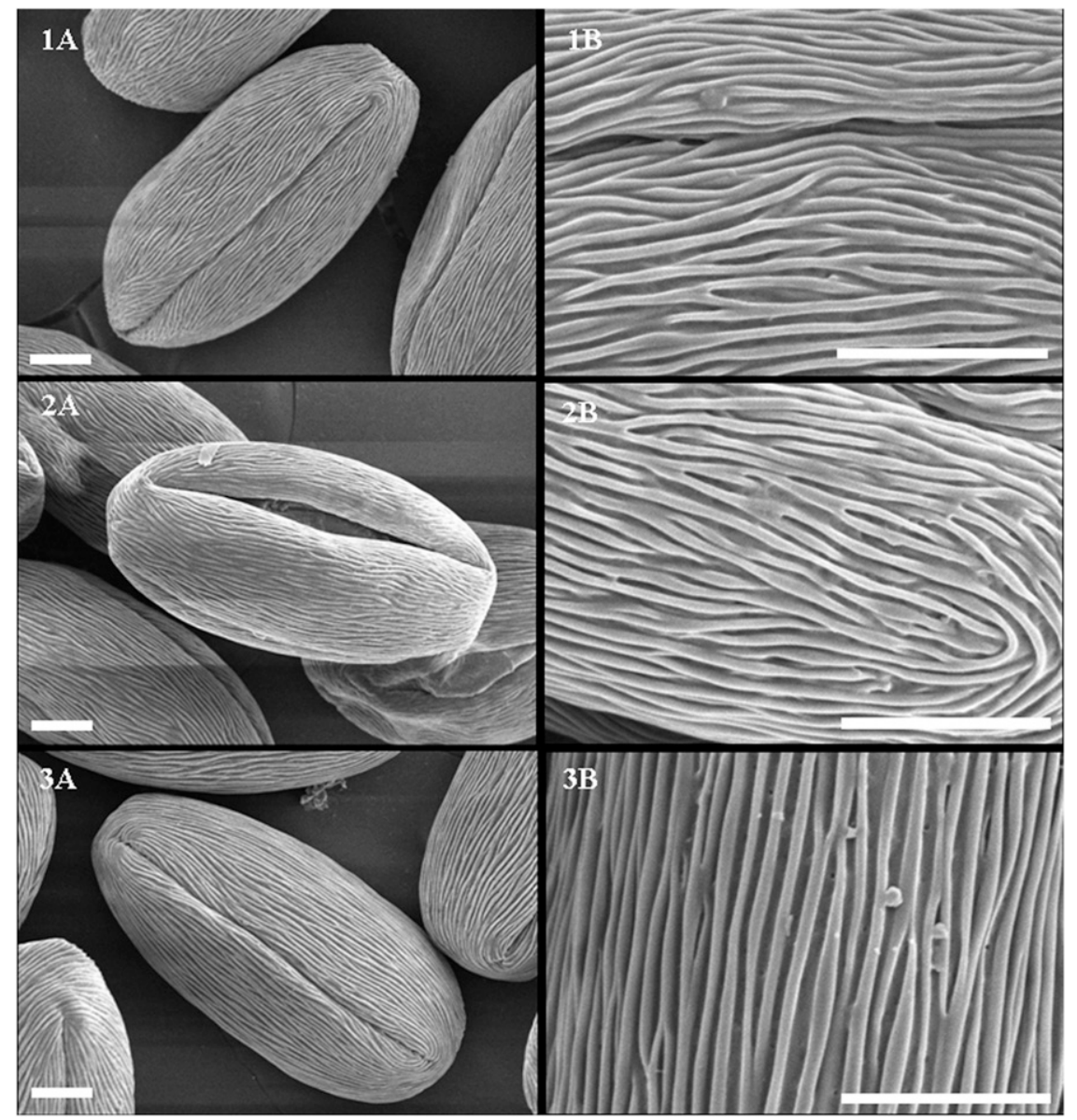

Fig. 3. Pollen morphous of P. mira from $3100 \mathrm{~m}$.

\section{Results}

Observation of pollen. The pollen measurement data are listed in Table 1. Figures 1 through 5 illustrate pollen characteristics from different altitudes. Although there is some variation, the pollen morphous of $P$. mira from different altitudes showed similar features. The pollen grains are perprolate, prolate, tricolporate, colpi monoprate, exine tectate, or equatorial outline trilobate. There is striate, striate-perforate, or irregular-perforate on sexine ornamentation. The length of equatorial axis ranges from 30.52 to 34.71 . The length of polar axis ranges from 60.45 to 68.14. The highest values of length of equatorial axis and polar axis are both from $3200 \mathrm{~m}$. The lowest values of length of equatorial axis and polar axis are both from $2900 \mathrm{~m}$. Thus, pollen grains from higher levels of altitude are larger than those from lower levels of altitude. Especially, there is an individual with diameter at breast height (DBH) $2.2 \mathrm{~m}$ and from altitude $3200 \mathrm{~m}$, which is different from the others. Its pollen grains are shown to be bigger and sharper but with an irregular morphous. We defined this pattern as irregular-perforate to separate it from others. A sample with DBH $0.7 \mathrm{~m}$ from altitude $3150 \mathrm{~m}$ also presents interesting differentiation, that is, it has no pollen grains that can be observed.

Using the data achieved by morphological measurements taken from pollen grains from five altitudes, cluster analyses were conducted (Fig. 6). The results of cluster analysis concluded that the samples from the same altitude were not clustered in one group but scattered in different groups.

RAPD polymorphism. After screening 50 primers, 12 primers were polymorphic and generated clear and repeatable bands among all individuals. The data on the TNB, the NPB, and the PPB are given in Table 2. Twelve primers generated 107 bands ranging from $200 \mathrm{bp}$ to $2000 \mathrm{bp}$. The number of bands for each primer range from four (Primer 30) to 11 (Primer 14 and Primer 47) with an average of 8.92 bands per primer. The RAPD profile amplified by the primer S14 is shown in Figure 7.

The mean GD among all genotypes is found to be 0.77 . Maximum pairwise GD (0.91) was found between 7 and 8 . The minimum pairwise GD $(0.22)$ was found when 4 was compared with 5 (data not shown).

Cluster analysis. The dendrogram based on GD was constructed (Fig. 3). The dendrogram showed that at 0.77 , all individuals were clearly clustered into six distinct groups: Group I, Group II, Group III, Group IV, Group V, and Group VI. Among them, Group I, Group II, Group III, and Group IV included one individual (Fig. 8). The individuals within the same group had the same altitude and different geographical distributions. For instance, 12, 13, and 14 in Group V were found to have the same altitude $(3200 \mathrm{~m})$. In contrast, three individuals $(1,2$, and 3$)$ belonging to the same altitude were separated into different groups. 


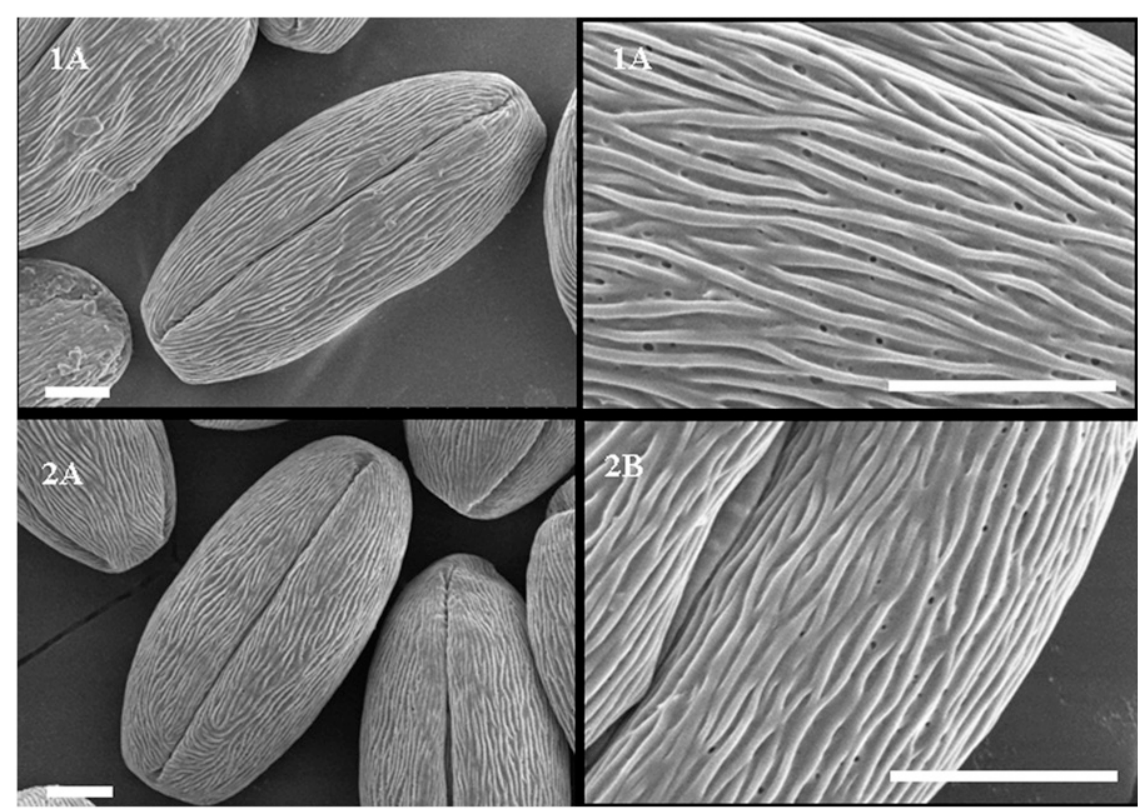

Fig. 4. Pollen morphous of $P$. mira from $3150 \mathrm{~m}$.

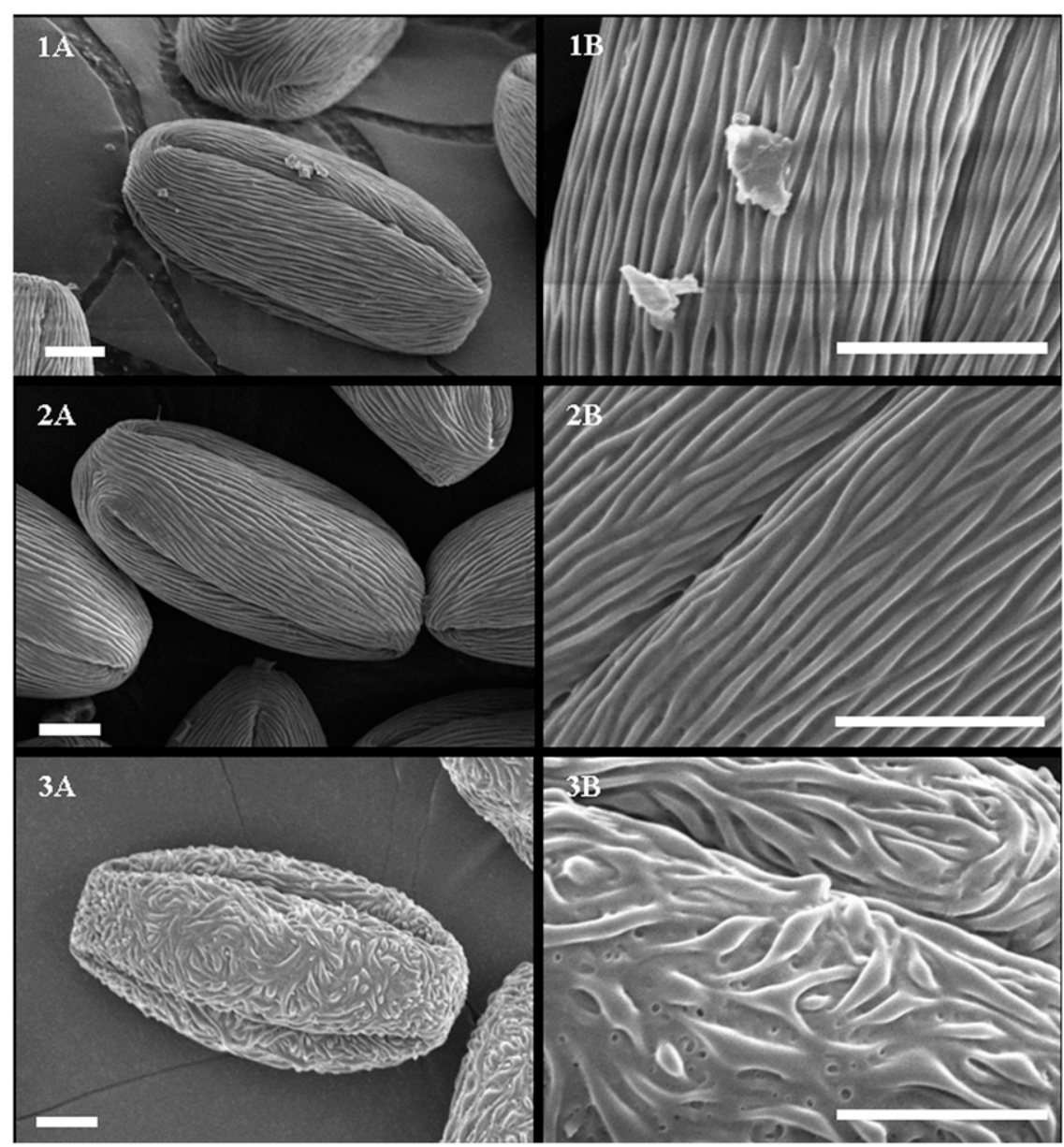

Fig. 5. Pollen morphous of $P$. mira from $3200 \mathrm{~m}$.

\section{Discussion}

To date, few researches focused on the relationship of the genetic structure of
2004) According to previous studies, remote geographical location can restrict the gene flow of the tree species and result in the differentiation of tree species. Generally, species at high altitudes in the species' range often show relatively high diversity (Lakhanpaul et al., 2000; Sagnard et al., 2002). Thus, accessions collected from different altitudes should have different genetic backgrounds. In contrast, some studies showed that no clear correlation could be made between altitude and GD; moreover, the species GD correlates with habit and region where there is excessive human activity (Dong, 1991). On the other hand, this is likely because some trees rely on wind pollination or insect pollinators.

This study uses pollen characteristics to determine relationships between pollen morphology and altitude. Some reports revealed that pollens of $P$. mira showed a relatively low level of evolutionary extent as a result of simple ornamentation because it is widely accepted that the order of the evolution of sexine ornamentation in the angiosperms pollen is from smooth to perforate (Guo et al., 2006; Socorro and Lorenzo, 2005). However, evolutionary extents of $P$. mira from different altitudes did not follow this pattern. Some pollen grains have perforated ornamentation; thus, they presented a higher evolutionary extent, whereas others with a blur sculpture and without perforate exhibited a lower evolutionary level. At the same time, most pollen grains from high altitudes are sharp with perforates. Especially, the individual sample from $3200 \mathrm{~m}$ and with DBH $2.2 \mathrm{~m}$ has typically irregular stripes, which separate it from others and may stand for a higher evolutionary level.

Thus, these characteristics suggest that pollen morphology of $P$. mira from different altitudes has high variation. In this study, it is illustrated that pollen grains of $P$. mira were different along varying altitudes and even within the same altitude. Previous researches also indicated that variation of pollen grains of a species depends on various genetic and environmental differences such as geographical conditions, climatic conditions, and altitudinal differentiation (Argant et al., 2006; Röpke et al., 2011; Rull, 2006; Rull et al., 2005, 2008). At the same time, many buds or flowers had no pollen grains; therefore, these individual may be male-sterile. This phenomenon needs further study. Although pollen of Prunus mira presents a high GD, pollen grains from lower altitudes are not as diverse as those from higher altitudes. Within $2900 \mathrm{~m}$, pollen grains are relatively similar to each other, including pollen size, sexine ornamentation, and other patterns. Perhaps to adapt to different environments, most samples on low altitude are seemingly original. In contrast, the evolutionary levels on higher altitudes are more developed. Additionally, we also found that the samples from same altitude were not clustered into one group, which may be a reason that these samples had different 


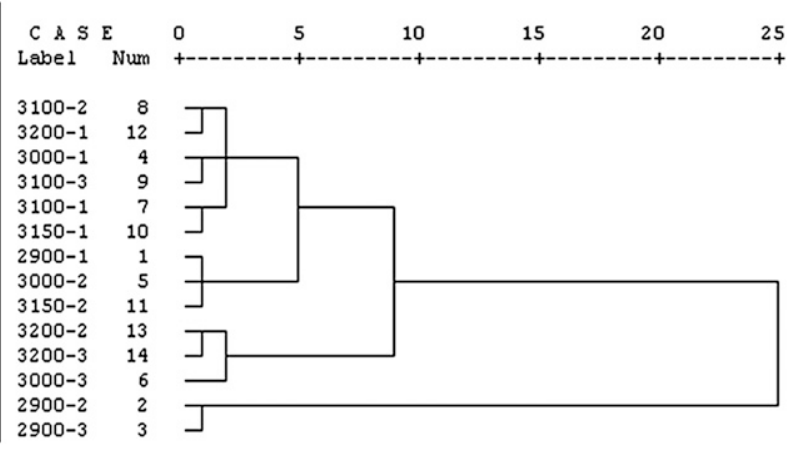

Fig. 6. The dendrogram according to the parameters from pollen morphous using SPSS 16.0 (SPSS Inc., Chicago, IL).

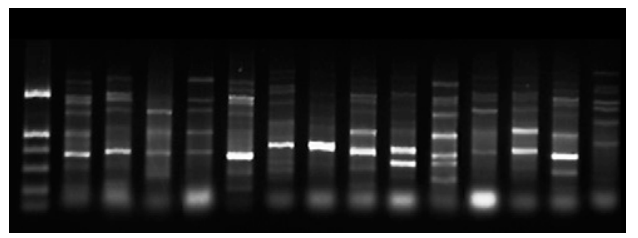

Fig. 7. Fingerprint patterns generated using primer S14 from the genomic DNA of the 14 genotypes of P. mira. genotypes in the study, the GD was low. Thus, these results demonstrated that the Prunus mira has a high genetic diversity, which was in agreement with the findings of Dong (1991).

Essentially, the level of genetic variability of plants is strongly related to many factors including plant life form, natural or artificial selection, and geographic site (Cuauhtemoc et al., 2006; Lakhanpaul et al., 2000). P. mira grows in marginal mountains or marginal streams, where environmental conditions are complicated. Accordingly, P. mira develops many variation types to adapt to different environments. Therefore, these biological characteristics may contribute to maintain a high level of genetic variability of $P$. mira by observation of pollen and detection of RAPD.

In summary, considering the small sample size, this study was preliminary. Nonetheless, pollen grains of $P$. mira indicate exciting variation, which provides valuable information for further study of the relationship between pollen morphology of $P$. mira and altitude; moreover, it provides reliable

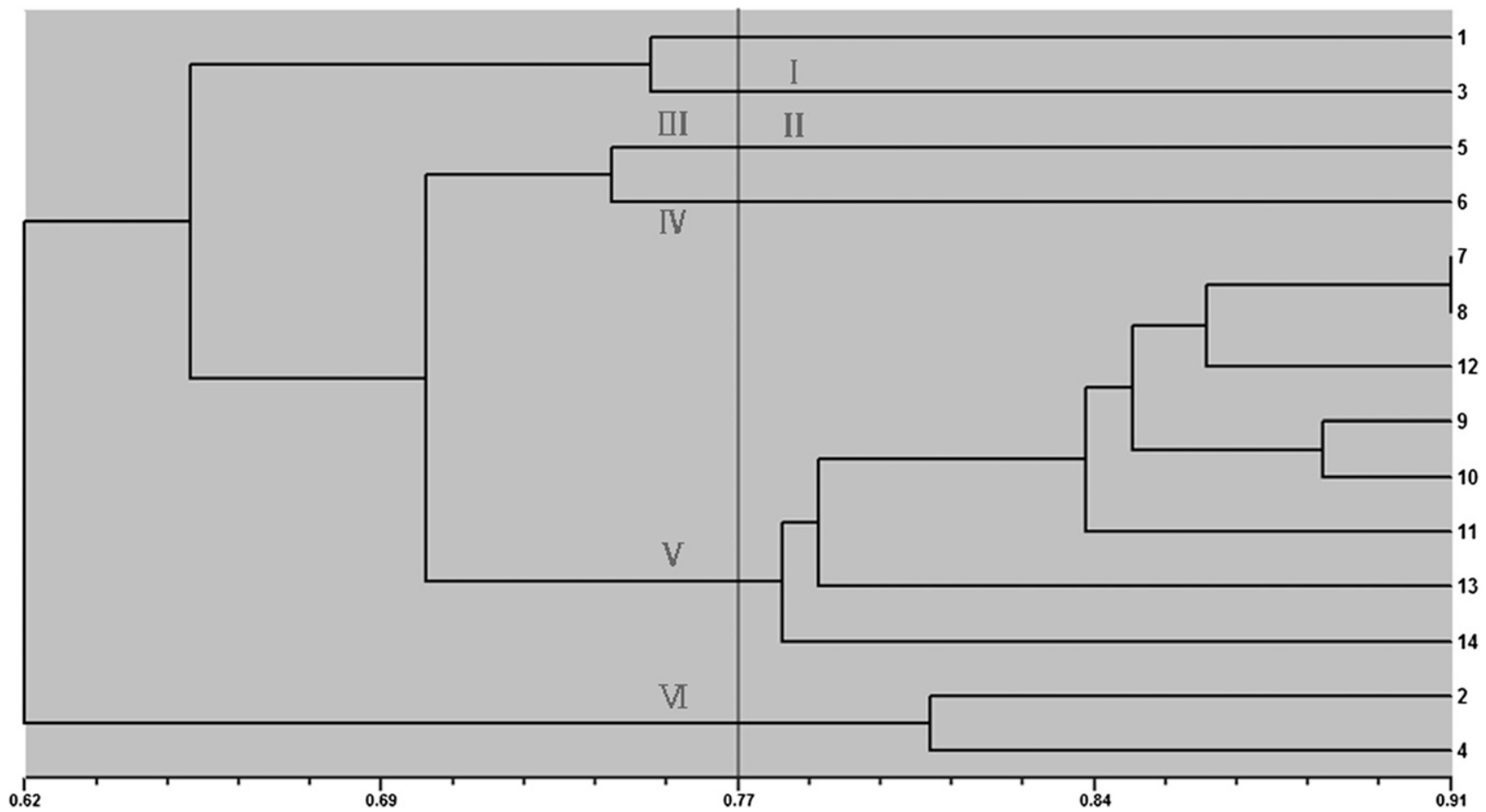

Fig. 8. Unweighted pair group method with arithmetic mean clustering based on genetic distance from random amplified polymorphic DNA data of 14 P. mira in this study.

diameters and at a certain height had different ages.

In addition, to further detect the level of genetic variability of $P$. mira, RAPD was also used to analyze the genetic relationship of $P$. mira from different altitudes. Based on RAPD, the analysis failed to show the same clustering of accessions sharing the same altitude. There were three possible explanations for this result. First, a stronger factor other than altitude determines GD. Second, the history of Prunus mira is long, which induces its high genetic variance. Third, this study involved a limited number of samples and did not cover the whole of the species' altitudinal range. Therefore, we need to examine more individuals to describe the total GD. Although we only sampled 15 information for the taxonomy of other peach species.

\section{Literature Cited}

Adekanmbi, O.H. and O. Ogundipe. 2006. Pollen grains of some cultivated plants in Nigeria. J. Sci. Res. Dev. 101-110.

Alfonso, H. and J.B. Bamberg. 2000. RAPD markers efficiently distinguish heterogenous 
populations of wild potato (Solanum). Genet. Resources Crop Evol. 47:115-121.

Argant, J., J.A. López-Sáez, and P. Bintz. 2006. Exploring the ancient occupation of a high altitude site (Lake Lauzon, France): Comparison between pollen and non-pollen palynomorphs. Rev. Palaeobot. Palynol. 141: 151-163.

Cuauhtemoc, S.R., R.R. Guzmán-Reyna, and G.E. Rehfeldt. 2006. Altitudinal genetic variation among Pinus oocarpa populations in Michoacán, Mexico: Implications for seed zoning, conservation, tree breeding and global warming. For. Ecol. Mgt. 229:340-350.

Debener, T., C. Bartels, and L. Mattiesch. 1996. RAPD analysis of genetic variation between a group of rose cultivars and selected wild rose species. Mol. Breed. 2:321-327.

Dong, G.Z. 1991. Investigation of Amygdalus mira in Tibet. Quarterly of Forest By-product and Specialty 44-45.

Guo, G., L. Wang, Z. Yan, G. Zhu, and W. Fang. 2006. Study on the variation and evolution of peach and its related wild species by pollen morphology. Journal of Fruit Science 5:002.

Hirao, A. and G. Kudo. 2004. Landscape genetics of alpine-snowbed plants: Comparisons along geographic and snowmelt gradients. Heredity 93:290-298.

Isik, K. and N. Kara. 1997. Altitudinal variation in Pinus brutia Ten. and its implication in genetic conservation and seed transfers in southern Turkey. Silvae Genet. 46:113-119.

Lakhanpaul, S., S. Chadha, and K. Bhat. 2000. Random amplified polymorphic DNA (RAPD) analysis in Indian mung bean [Vigna radiata (L.) Wilczek] cultivars. Genetica 109:227-234.

Lin, K., H. Lo, S. Lee, C. George Kuo, J. Chen, and W. Yeh. 2006. RAPD markers for the identification of yield traits in tomatoes under heat stress via bulked segregant analysis. Hereditas 143:142-154.

Liu, H., Y. Gao, W. Ruan, L. Chen, C. Li, N. Zhao, and D. Wang. 2004. Genetic differentiation within and between Leymus chinensis populations from different zones of Mid-Eastern Inner Mongolia steppe. Acta Ecol. Sin. 24:2157-2164.

Marotti, I., A. Bonetti, M. Minelli, P. Catizone, and G. Dinelli. 2007. Characterization of some Italian common bean (Phaseolus vulgaris L.) landraces by RAPD, semi-random and ISSR molecular markers. Genet. Resources Crop Evol. 54:175-188.

Noor, M.J., M. Ahmad, R. Asghar, A. Kanwal, and S. Pervaiz. 2004. Palynological studies of cultivated plant species at University of Arid Agriculture, Rawalpindi, Pakistan. Asian J. Plant Sci. 3:476-479.

Oswald, W., E. Doughty, G. Ne'eman, R. Ne'eman, and A. Ellison. 2011. Pollen morphology and its relationship to taxonomy of the genus Sarracenia (Sarraceniaceae). Rhodora 113:235-251.

Perveen, A. and M. Qaiser. 2010. Pollen flora of Pakistan-LXV. Berberidaceae. Pak. J. Bot. 42:1-6.

Rohlf, F.J. 1992. NTSYS-pc: Numerical taxonomy and multivariate analysis system. Exeter Publishing, Setauket, NY.

Röpke, A., A. Stobbe, K. Oeggl, A.J. Kalis, and W. Tinner. 2011. Late-Holocene land-use history and environmental changes at the high altitudes of St Antönien (Switzerland, Northern Alps): Combined evidence from pollen, soil and treering analyses. Holocene 21:485-498.

Rull, V. 2006. A high mountain pollen-altitude calibration set for palaeoclimatic use in the tropical Andes. Holocene 16:105-117.

Rull, V., M.B. Abbott, P.J. Polissar, A.P. Wolfe, M. Bezada, and R.S. Bradley. 2005. 15,000-yr pollen record of vegetation change in the high altitude tropical Andes at Laguna Verde Alta, Venezuela. Quat. Res. 64:308-317.

Rull, V., A. José L.S., and V.V. Teresa. 2008. Contribution of non-pollen palynomorphs to the paleolimnological study of a high-altitude Andean lake (Laguna Verde Alta, Venezuela). J. Paleolimnol. 40:399-411.

Sagnard, F., C. Barberot, and B. Fady. 2002. Structure of genetic diversity in Abies alba Mill. from southwestern Alps: Multivariate analysis of adaptive and non-adaptive traits for conservation in France. For. Ecol. Mgt. 157:175-189.

Socorro, L. and V. Lorenzo. 2005. A high-elevation Holocene pollen record from Iztaccíhuatl volcano, central Mexico. Holocene 15:329-338.

Tan, J.P., X.L. Zeng, M.A. Liao, L.N. Qiu, Y.X Wang, and Z.G. Ciren. 2001. Optimization for SRAP-PCR system and selection of primers on Prunusmira Koehne from Tibet. Northern Horticulture 2:139-143.

Wang, J., S. Hu, and Z. Wang. 1997. A comparative study on the photosynthetic characteristics of Tibetan Prunus mira (Koehne) Kov et. Kpst with cultivated peach. Acta Horticulturae Sinica 24:197-198. 